\section{On best practice}

As we ring in the new year, it is an opportune time to consider the work that we all do, celebrate it, and reflect on it-particularly those best practices and innovations in the profession that may further the trajectory and impact of our work.

As we talk about librarianship and the work of academic libraries and librarians, we often point to best practices, case studies, and lessons learned. Far beyond the "how we done it good" article, they help identify excellence and innovation as well as provide a clear line of sight between research and its application. College \& Research Libraries and College \& Research Libraries News are flip sides of that coin. CERL News focuses primarily on practice from a personal and institutional experience perspective, including innovative projects, enhanced services, collaborations across campus, best practices in teaching, and new applications of technology. The day-to-day tip of the iceberg of librarianship in practice, so to speak.

$C G R L$ is the rest of the iceberg-the larger implications of the research, the complex methodologies that go into analytical studies, the theoretical foundations, and the model building. CERL News often is more accessible to the library practitioner with local accounts and commentaries that may be adopted or readily adapted. CERL provides a deeper examination of topics and the broader implications for libraries and higher education. The two publications tend to meet in the middle with their reporting or examinations of best practice.

Ironically, while best practice gets the most attention, worst practice is also useful and in some ways, more so. However, the literature rarely recounts resounding failures,

Wendi Kaspar is C\&RL editor and policy sciences librarian at the Texas A\&M University Policy Sciences and Economics Library, email: warant@library.tamu.edu even though they, too, would provide valuable guidance and insights either as cautionary tales or methods to avoid. Ironically, there are many best practices that ultimately don't turn out or end up not being sustainable, but there is no follow-up or reporting on them.

The preponderance of articles in the January issue of $C \& R L$ are from a case study perspective, either evaluating local practice at an institution or a comparative study between two institutions and the potential for broader impact on the profession.

"Library User Education as a Window to Understand Inquiry-Based Learning in the Context of Higher Education in Asia: A Comparative Study between Peking University and the University of Tsukuba" by Qianxiu Liu, Bradley Allard, Patrick Lo, Qingshan Zhou, Tianji Jiang, and Hiroshi Itsumura. This study is based on the belief of that inquirybased learning should be made an integral part of any student's learning, especially at university level. To find out the students' perceptions towards library user education, 426 questionnaire surveys have been collected from the Peking University (PKU) China and the University of Tsukuba (UT) Japan. The results of this study indicate that compared with UT, PKU students on the whole expressed higher ratings in many areas towards the user education programs provided by their respective library, and they also had a more positive view about the professional competence of the user education (reference services) librarians. The researchers believed that the different perceptions found between the PKU and UT groups were a direct result of the distinctive learning practices and curricular requirements exercised between the two universities. There are not many articles that explore the relation between inquirybased learning and the library user education in Asia. The findings of this study are useful for identifying the different learning modes among these two groups of students, as 
well as other barriers that were preventing the library user education programs to be integrated into inquiry-based learning, and the university's core curriculum as a whole.

"Authentic Assessment of Student Learning in an Online Class: Implications for Embedded Practice" by Jessica Alverson, Jennifer Schwartz, and Sue Shultz. According to the 2017 Distance Education Enrollment Report, the number of students enrolled in online courses has been increasing year after year, with more than 6 million students taking at least one online course in 2015. The students who are enrolled in online classes, however, aren't always prepared for the work expected of them. One survey conducted in 2016 found that nearly $60 \%$ of faculty who engage in online teaching strongly agree that their undergraduate students have poor research skills, especially related to finding and evaluating scholarly information. In response, teaching faculty have become more reliant on librarians as experts to help students master these skills. Embedded librarianship, defined as having professional librarians interact with students directly through the learning management system, has been employed as one strategy for meeting the needs of these online students.

"Research Is an Activity and a Subject of Study: A Proposed Metaconcept and Its Practical Application" by Allison Hosier. Information literacy instruction based on the ACRL Information Literacy Competency Standards for Higher Education tends to focus on basic research skills. However, research is not just a skill but also a subject of study. The ACRL Framework for Information Literacy for Higher Education opens the door to integrating the study of research into information literacy instruction via its acknowledgement of the contextual nature of research. This article introduces the metaconcept that research is both an activity and a subject of study. The application of this metaconcept in core LIS literature is discussed, and a model for incorporating the study of research into information literacy instruction is suggested.

"Electronic Theses and Dissertations Programs: A Review of the Critical Success Factors" by Behrooz Rasuli, Sam Solaimani, and Mehdi Alipour-Hafezi. Electronic Theses and Dissertations (ETDs) programs have been recognized as one of the most effective channels through which theses and dissertations can be made available to academic communities and beyond. ETD program management, however, needs to be aware of the Critical Success Factors (CSFs) throughout the process of design and development of ETDs. As the name implies, CSFs are those considerations decisive in achieving the project's mission and goals. Based on a structured review of the existing literature about ETDs, this study identifies the CSFs that are crucial for the implementation of ETD programs. By comparing and classifying the identified CSFs, the study conceptualizes a generic framework comprised of five generic dimensions: management and organization, participation, content, technology, and service. The framework can help the ETDs community, both scholars and practitioners, to make informed decisions on how to allocate effort and resources to the development, implementation, or improvement of ETD programs.

"Using Data Mining for Citation Analysis" by Philip B. White. This paper presents a new model for citation analysis, applying new methodological approaches in citation studies. These methods are demonstrated by an analysis of cited references from publications by the Geological Sciences faculty at the University of Colorado-Boulder. The author made use of simple Python scripting, the Web of Science API, and OpenRefine to examine the most frequently cited journals and compare them to library holdings data to discover materials absent from the local collection. Of the more than 20,000 citations analyzed, 80 percent cited approximately 10 percent of all titles (412 journals). A notable finding 
was the heavy reliance of faculty members upon works between zero and two years of age. The streamlined model presented here removes the constraints of time and effort encountered by academic librarians interested in conducting citation analyses.

"Instruction and Outreach for Transfer Students: A Colorado Case Study by Lindsay Roberts, Megan E. Welsh, and Brittany Dudek." Studies of transfer student success abound in higher education, yet few studies examine the role that academic libraries play in students' transitions. This study explores the academic library services offered to transfer students in Colorado through a survey of librarians. What are barriers to offering these services? How do library professionals perceive instruction and outreach to transfer students? Results show differences between attitudes and practice, even within the same institution, and suggest opportunities for future collaboration among two-year and four-year academic libraries in Colorado. The article discusses these findings in the context of findings from New York and Ohio studies, suggesting academic libraries need greater awareness of, and services for, transfer students.

"Visual Literacy in Practice: Use of Images in Students' Academic Work" by Krystyna K. Matusiak, Chelsea Heinbach, Anna Harper, and Michael Bovee. Digital technology has changed the way in which students use visual materials in academic work and has increased the importance of visual literacy skills. This paper reports the findings of a research project examining undergraduate and graduate students' visual literacy skills and use of images in the context of academic work. The study explored types of visual resources used, the role that images play in academic papers and presentations, and the ways students select, evaluate, and process images. The findings of the study indicate that students lack skills in selecting, evaluating, and using images. Students use a range of visual resources in their presentations but rarely use images in papers. $\boldsymbol{n}$

\section{NEW FROM ACRL PRESS}

\section{Transforming Libraries to Serve Graduate Students edited by Crystal Renfro and Cheryl Stiles}

Both available now in the ALA Store at http://www.alastore.ala.org
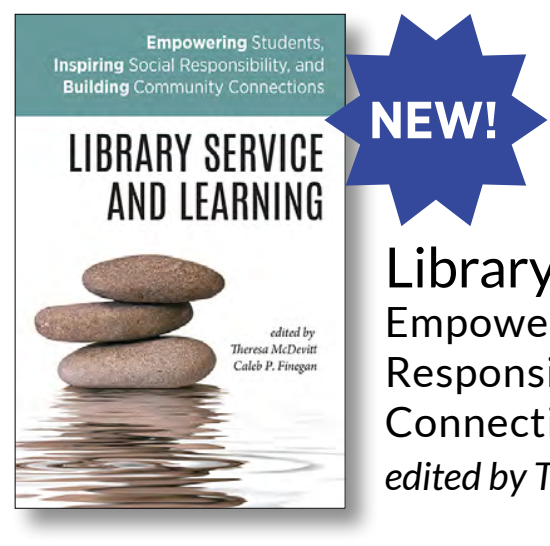

Library Service and Learning: Empowering Students, Inspiring Social Responsibility, and Building Community Connections edited by Theresa McDevitt and Caleb P. Finegan 